\title{
A Study on Measurement and Emission Reduction of Carbon Emissions in Automobile Supply Chain
}

\author{
Yu Chen ${ }^{\mathrm{a}}$, Zhigao Liao ${ }^{\mathrm{b}}$, Yanling $\mathrm{Wu}^{\mathrm{c}}$ \\ School of Management, Guangxi University of Science \& Technology, Liuzhou 545006, China. \\ acy31600@163.com, b46154910@qq.com, cwyl521510@163.com
}

Keywords: Automobile supply chain, Carbon emission measurement, Energy conservation and emissions reduction.

\begin{abstract}
This paper has calculation of carbon emissions from the perspective of supply chain to analyze the corresponding ways to reduce emissions. Through the statistics of the energy consumption data of automobile supply chain, this paper selects the carbon emission accounting method that is suitable for automobile industry, analyzes and compares the energy consumption and carbon emission in each link of the automobile supply chain, sets up the carbon emission accounting model of the automobile supply chain, and solves the model by using the calculation examples. According to the calculation and analysis of the model, it finds that the proportion of $\mathrm{CO}_{2}$ produced by automobile production links (automobile production enterprises) is larger, while the $\mathrm{CO}_{2}$ produced by the recovery link is smaller. In the production process, the $\mathrm{CO}_{2}$ produced by the painting workshop produces is the most. Through analysis, it concludes that automobile supply chain can reduce emissions through internal improvement of equipment and technology, and the establishment of cooperation alliance among supply chain members and other ways.
\end{abstract}

\section{Introduction}

With the development of economy, the emission of $\mathrm{CO}_{2}$ is increasing continuously. According to statistics, the emission of $\mathrm{CO}_{2}$ in the world is 40 billion tons in 2002 and 58 billion tons in 2030 [1]. Faced with the grim reality, many countries and regions in the world have taken measures to develop low-carbon economy. On December 19, 2017, the national development and reform commission issued "the national carbon emissions trading market construction scheme (power generation), marking the carbon emissions trading system in our country completed the overall design, and officially launched. The official launch of the national carbon trading market will have a profound impact on the internal management, decision-making and investment of enterprises. According to statistics, in developed countries with mature automobile industry, the carbon emission of automobile industry accounts for $25 \%$ to $28 \%$ of the total carbon emission [1]. In this context, this paper will calculate and propose the corresponding emission reduction strategies by establishing the model and calculating the $\mathrm{CO}_{2}$ produced by each link of the automobile supply chain. Previous studies of carbon emissions are relatively abundant, mainly focuses on the two-way causal relationship between carbon emissions and economic growth [2] and the industrial structure, energy structure, the influence of population on carbon emissions, etc. [3-4], gradually turned to the existing research to quantify the carbon emissions, so that you can more on mitigation measures. The calculation of carbon emissions is generally divided into two types: top down and bottom up. Top-down accounting system is mainly based on the national or regional accounting, such as Shou-Hong Xie [5] by the IPCC listing method, calculate the transportation industry in China in 1980-2012 carbon emissions; Bottom-up accounting system mainly refers to products, enterprises and projects, such as Tie-Shan Zhang ${ }^{[1]}$ through a comprehensive comparison of carbon accounting methods, selected the discharge coefficient method, the carbon emissions of auto manufacturing production process calculation, puts forward the government, enterprise and energy suppliers tripartite joint reduction proposal. In this paper, based on the automobile supply chain as the research object, and carbon emissions coefficient method was 
used to construct automobile supply chain carbon emissions calculation model, lay a foundation for more effective carbon reduction.

\section{Problem Description and Model Hypothesis}

\subsection{Measurement of Carbon Emission.}

And discharge coefficient method is the IPCC carbon technology guidelines provide energy consumption carbon emissions calculation mode, refers to under the condition of normal technical economy and production management, production of gas emission quantity per unit product of statistical average. The calculation formula of emission coefficient method [6] is shown in equation:

\subsection{Determination of Carbon Emission Factors.}

$$
\mathrm{C}=\Sigma \mathrm{C}_{\mathrm{i}}=\Sigma \mathrm{E}_{\mathrm{i}} \times \mathrm{F}_{\mathrm{i}}
$$

According to the different types of energy, the emission factors are divided into direct and indirect emission factors [7]. The direct emission factor refers to the $\mathrm{CO}_{2}$ emitted by the enterprise in the process of production, such as oil and natural gas consumption, as shown in Tab 1. Indirect emission factors are used in the production of enterprises, but the emission occurs in the emission sources controlled by other enterprises, such as electricity. In all of the formulas in this paper, $\mathrm{H}$ is used to express direct or indirect emission coefficients, such as the emission coefficient of diesel for diesel.

Table 1. Emission factor of direct emission factor

\begin{tabular}{cccccc}
\hline $\begin{array}{c}\text { The name } \\
\text { of the } \\
\text { energy }\end{array}$ & $\begin{array}{c}\text { Average low } \\
\text { heat }\end{array}$ & $\begin{array}{c}\text { The unit calorific value is } \\
\text { carbon(/t C/TJ) }\end{array}$ & $\begin{array}{c}\text { Carbon } \\
\text { oxidation rate }\end{array}$ & $\begin{array}{c}\text { The ratio of } \mathrm{CO}_{2} \\
\text { to carbon }\end{array}$ & $\begin{array}{c}\text { Discharge } \\
\text { coefficient }\end{array}$ \\
\hline $\begin{array}{c}\text { The raw } \\
\text { coal }\end{array}$ & $20908 \mathrm{KJ} / \mathrm{kg}$ & 26.37 & $94 \%$ & 3.6667 & $1.9003 \mathrm{kgCO}_{2} / \mathrm{kg}$ \\
$\begin{array}{c}\text { Natural gas } \\
\text { gasoline }\end{array}$ & $38931 \mathrm{KJ} / \mathrm{m}^{3}$ & 15.3 & $99 \%$ & 3.6667 & $2.1622 \mathrm{~m}^{3} \mathrm{CO}_{2} / \mathrm{kg}$ \\
kerosene & $43070 \mathrm{KJ} / \mathrm{kg}$ & 18.9 & $98 \%$ & 3.6667 & $2.9251 \mathrm{kgCO}_{2} / \mathrm{kg}$ \\
diesel & $42652 \mathrm{KJ} / \mathrm{kg}$ & 19.5 & $98 \%$ & 3.6667 & $3.0179 \mathrm{kgCO}_{2} / \mathrm{kg}$ \\
\hline
\end{tabular}

\subsection{Definition of Automobile Supply Chain.}

Article according to the structure of the automotive supply chain and analyzes the automobile supply chain carbon emissions associated with social, environmental, and economic system, construct the automobile supply chain system of carbon emissions. Carbon emission measurement in automobile supply chain is mainly carried out in the following aspects: procurement, production, sales and recycling. Purchasing carbon emissions of $\mathrm{CO}_{2}$ mainly raw materials suppliers, distributors and sales of carbon emissions is of $\mathrm{CO}_{2}$, carbon emissions is the core enterprise production of $\mathrm{CO}_{2}$ automobile production enterprises, recycling of carbon emissions is dispersed in each supply chain member enterprises.

\section{Calculation of Carbon Emission in Automobile Supply Chain}

According to the definition of automobile supply chain, this paper carries on the calculation of carbon emission in automobile supply chain from four aspects, namely, procurement, production, sales and recycling, namely:

\subsection{Procurement of Carbon Emissions.}

$$
\mathrm{E}_{\mathrm{CO}_{2}}=\mathrm{E}_{\text {procurement }}+\mathrm{E}_{\text {production }}+\mathrm{E}_{\text {sales }}+\mathrm{E}_{\text {recycling }}
$$

The carbon emission produced by the purchasing process of automobile supply chain is mainly converted into the transportation of parts and the calculation of carbon emission from the storage process.

The carbon emission of automobile supply chain is mainly embodied in the carbon emission and storage carbon emission of parts and components, and the procurement and warehousing raw materials are all $\mathrm{Q}_{1}(\mathrm{t})$. The transportation sharing rate of railways, highways and waterways is $\mathrm{Ni}_{\mathrm{i}} \mathrm{N}_{\mathrm{J}}$ and $\mathrm{n}_{\mathrm{o}}$, and the three modes of transportation are able to transport all the raw materials. In railway transportation, the ratio of electric locomotive and fuel locomotive is $\mathrm{y}_{1}, \mathrm{y}_{2}$; The average 
transportation distance of railway, waterway and highway is $\mathrm{L}_{1}, \mathrm{~L}_{2}, \mathrm{~L}_{3}(\mathrm{Km})$, and oil consumption per kilometer is $X_{1}, X_{2}, X_{3}(\mathrm{~kg} /(T . K . M))$; The combustion value of type a fuel is q (TJ/kg); When the raw materials of the warehouse are stored, the space of $M(\mathrm{~m} 3)$ is required, and the power consumption per cubic meter is $\mathrm{p}(\mathrm{m} 3 / \mathrm{KWH})$, i.e.

$$
\begin{aligned}
& \mathrm{E}_{\text {procurement }}=\mathrm{Q} \times \mathrm{n}_{\mathrm{i}} \times \mathrm{L}_{1} \times \mathrm{X}_{1} \times \mathrm{q} \times \mathrm{y}_{1} \times \mathrm{H}_{\text {diesel }}+\mathrm{Q} \times \mathrm{n}_{\mathrm{i}} \times \mathrm{L}_{1} \times \mathrm{X}_{1} \times \mathrm{q} \times \mathrm{H}_{\text {electricity }}+ \\
& \mathrm{Q} \times \mathrm{n}_{2} \times \mathrm{L}_{2} \times \mathrm{X}_{2} \times \mathrm{q} \times \mathrm{H}_{\text {diesel }}+\mathrm{Q} \times \mathrm{n}_{3} \times \mathrm{L}_{3} \times \mathrm{X}_{3} \times \mathrm{q} \times \mathrm{H}_{\text {diesel }}+\mathrm{M} \times \mathrm{p} \times \mathrm{H}_{\text {electricity }}
\end{aligned}
$$

\subsection{Production of Carbon Emissions.}

Auto production process is composed of multiple independent processes, these processes to streamline production, completed by the professional manufacturing equipment, mainly in the production process of carbon from the consumption of manufacturing equipment of fossil energy, such as direct emissions and indirect emissions of electricity consumption etc. Auto production process including stamping, welding, painting and assembly four process and other links [1].

The stamping process is mainly used to power the stamping equipment, and the general assembly process can also consume power for the assembly equipment. The two processes consume only electricity and the calculation method is the same. The total power consumption of the stamping process is $\mathrm{D}_{1}(\mathrm{KWh})$, and the total power consumption is $\mathrm{D}_{2}(\mathrm{KWh})$. Welding technology mainly used for power equipment, but because the welding process directly from carbon dioxide into the atmosphere is not easy to measure and account for less, therefore, this article does not consider the welding process directly from carbon dioxide into the atmosphere. The total power consumption of welding process is $\mathrm{D}_{3}(\mathrm{KWh})$.Coating process of energy dissipation are mainly electricity, gas, steam, etc., coating process, respectively set up a total power consumption of $\mathrm{D}_{4}(\mathrm{KWh})$, the amount of consumption of natural gas for $F_{1}\left(m_{3}\right)$, the total consumption of steam for $\mathrm{G}_{1}(\mathrm{t})$. Other carbon dioxide amount is in addition to the above four process including office building, canteen facilities, energy consumption of main energy into electricity and natural gas, set the total power consumption for $\mathrm{D}_{5}$ (KWh), the amount of consumption of natural gas is $\mathrm{F}_{2}\left(\mathrm{~m}_{3}\right)$

$$
\begin{gathered}
\mathrm{E}_{\text {production }}=\mathrm{D}_{1} \times \mathrm{H}_{\text {electricity }}+\mathrm{D}_{2} \times \mathrm{H}_{\text {electricity }}+\mathrm{D}_{3} \times \mathrm{H}_{\text {electricity }}+\mathrm{D}_{4} \times \mathrm{H}_{\text {electricity }} \text { ? } \mathrm{F}_{1} \times \mathrm{H}_{\text {natural gas }}+\mathrm{G}_{1} \times \mathrm{H}_{\text {steam }}+ \\
\mathrm{D}_{5} \times \mathrm{H}_{\text {electricity }}+\mathrm{F}_{2} \times \mathrm{H}_{\text {natural gas }}
\end{gathered}
$$

\subsection{Sales of Carbon Emissions.}

The carbon emission produced in the sales process of automobile supply chain is mainly converted into the transportation carbon emission of the automobile sales process and the carbon emission generated in the process of automobile sales. The carbon emission produced by the automobile supply chain sales process is similar to the carbon emission measurement model of the procurement process, thus the carbon emission generated by automobile transportation in the sales process. Assuming that the vehicle traffic volume is $\mathrm{Q}_{2}(\mathrm{t})$, other factors are the same as the Procurement of carbon emissions.

\subsection{Recovery of Carbon Emissions.}

The core enterprise of automobile supply chain needs not only to pay attention to the emission reduction of its own production process, but also to consider the emission reduction of the product life cycle in the supply chain [9]. The whole process of automobile supply chain includes not only procurement, production and sales, but also recycling. The recycling process mainly consists of two ways: remanufacturing, discarding and re-turning into raw materials. Remanufacturing mainly consumes electricity, natural gas and steam, while the main energy consumed by waste is energy. The remanufacturing process consumes power $\mathrm{D}_{6}(\mathrm{KWh})$, consumes natural gas $\mathrm{F}_{3}\left(\mathrm{~m}^{3}\right)$, consumes steam $\mathrm{G}_{2}(\mathrm{t})$, and wastes the power consumption of the raw material, $\mathrm{D}_{6}(\mathrm{~K}$ Why), then:

$$
\begin{gathered}
\mathrm{E}_{\text {recycling }}=\mathrm{E}_{\text {reprocessing }}+\mathrm{E}_{\text {abandoned }}=\mathrm{D}_{6} \times \mathrm{H}_{\text {electricity }} \text { ! } \\
+\mathrm{H}_{3} \times \mathrm{H}_{\text {natural gas }}+\mathrm{G}_{2} \times \mathrm{H}_{\text {steam }}+\mathrm{D}_{6} \times \mathrm{H}_{\text {electricity }}
\end{gathered}
$$




\section{Case Analysis}

According to the data obtained [1, 7, 8], taking A car company as an example, the carbon emission calculation model of automobile supply chain is verified. According to the theory and model of this paper, the carbon emission data of each stage of a company's production of a car supply chain is shown in Tab 2.

Table 2. Carbon emissions at various stages of the supply chain of an automobile enterprises

\begin{tabular}{ccc}
\hline Carbon emission type & Carbon emissions(t) & The proportion \\
\hline Procurement of carbon emissions & 9891.220 & $12 \%$ \\
Production of carbon & 58523.056 & $71 \%$ \\
Selling carbon emissions & 10715.489 & $13 \%$ \\
Recovery of carbon emissions & 3297.074 & $4 \%$ \\
A combined & 82426.839 & \\
\hline
\end{tabular}

\section{Analysis of Calculation Results}

(1) Based on A car enterprise supply chain's stage, the calculation of carbon emissions of $\mathrm{CO}_{2}$ in the automotive supply chain for A total of 82426.839 tons each workshop production of $\mathrm{CO}_{2}$ emissions is 58523.05 tons, accounting for about $71 \%$ of the total, the proportion of larger, there is $\mathrm{A}$ big space to reduce emissions, is the national key object. However, the $\mathrm{CO}_{2}$ emissions generated by other parts of the supply chain (members) account for only $29 \%$ of the total $\mathrm{CO}_{2}$ emissions in the supply chain, but they should also take measures to implement unified supervision. Therefore, it is an effective way for automobile industry to reduce carbon emission in the automobile industry by establishing a cooperative alliance led by automobile manufacturers.

(2) In the process of car production, produce the most $\mathrm{CO}_{2}$ workshop is painting workshop, accounts for about $45 \%$ of the whole production process, after welding workshop is $19.27 \% 15.3 \%$, other $15.3 \%$, final assembly workshop, stamping workshop is $7.24 \%$, at least fully verified the "large in automobile manufacturing enterprise, the technology of energy dissipation is coating workshop". Coating workshop of a series of processes such as water washing, degreasing, phosphate, electrophoresis and so on need to consume large amounts of energy, to produce a large number of $\mathrm{CO}_{2}$ emissions at the same time, therefore, energy-saving technology development and application of the coating should be auto industry important way of energy saving.

\section{Summary}

In this paper, by using the IPCC emission coefficient method recommended by supply chain each link to A car enterprise energy consumption statistical data, and analyzes the automobile supply chain each link of $\mathrm{CO}_{2}$, to quantify the supply chain of each link in the process of $\mathrm{CO}_{2}$ emissions, for the other car companies supply chain effectively to carry out the energy conservation and emissions reduction, reduce carbon emissions, improve the efficiency of enterprises to provide certain scientific basis. (1) Through the analysis of the results found that in the automotive supply chain production energy consumption is larger, or more of $\mathrm{CO}_{2}$, and so the car industry emissions, should from the production process. Auto production enterprise should improve and perfect enterprise management system, low carbon production as the core, determined in accordance with the national energy strategy, and the requirement of discharge standard structure, draw lessons from international advanced production experience, the introduction of overseas professionals training local talents;(2) When the automobile industry undertakes emission reduction, it should also be carried out from the supply chain level. Among the member enterprises of the supply chain, the alliance should be established and the joint emission reduction should be implemented. The members of the supply chain should strengthen the horizontal communication and cooperation among the members, and establish a cooperative alliance based on the automobile production enterprises. The cooperative alliance can jointly develop and promote new technologies, improve the comprehensive strength of research and development, and at the same time share costs and reduce risks. Finally, the cooperation 
alliance should establish an internal carbon accounting department, which can effectively promote the emission reduction of each member according to the allocation of carbon quota according to the emission reduction of each member. The supply chain cooperation alliance, through the combination of strong and strong, can complement each other and optimize the allocation of resources so as to enhance the international competitiveness and promote the development of China's automobile industry.

\section{Acknowledgments}

We acknowledge the support of Guangxi Philosophy and Social Sciences Research Topics” Effects of Carbon Trading on Guangxi's Manufacturing Carbon Emissions and Countermeasures” (17FJY007).

\section{References}

[1]. Tyesha Zhang, Xiaoshuang Chen. The Calculations and Strategies on Carbon Emission in Production Process of Automobile Manufacturing Enterprises [J]. Enterprise Economy, 2014, 33 (10): 17-21.

[2]. Waken $\mathrm{OH}$, Kimono Lee. Energy Consumption and Economic Growth in Korea: Testing the Causality Relation [J]. Journal of Policy Modeling, 2004, 26(8-9):973-981.

[3]. Jian Feng Hu, Hue Shi. Low-carbon Economic Development Target and Implementation Plan -Taking the Yangtze River Delta as an Example [J]. Financial Research, 2012, 38 (3): 81-92.

[4]. Chenyao Qu, Lianshui Li, Zhonghua Cheng. China's Manufacturing Energy Efficiency and Its Influencing Factors [J]. Technology Management Research, 2016, (15): 128-135.

[5]. Shooing Xin, Haiyan CAI. The Calculation and Influencing Factors of Carbon Emissions in China's Transportation Industry [J]. Resources and Environment in Arid Areas, 2016, 30 (05): 13-18.

[6]. Yan Wang, Pyongyang Huang, et al. The Development and Application of the Software for Accounting for Pollutant Discharge Quantity in Complex Chemical Process Based on Material Balance Algorithm [J]. Environmental Protection Science, 2010, (2).

[7]. Zhenjiang Zhao, Peng Zhang, Mingnan Zhao. The Analysis of Energy Consumption and Carbon Emissions in the Automobile Manufacturing Process [J]. China Population, Resources and Environment, 2017, 27 (S1): 186-190.

[8]. Qi Li, Xi Bai. The Estimation and Governance in Supply Chain of Carbon Footprint: A Case Study of Guangdong Automobile Industry [J]. China's Circulation Economy, 2013, 27 (12): 37-44.

[9]. Zheng Sun, Fengzhong Wang, Gang Ying. A Research on Production and Emission Reduction Mechanism of Supply Chain Enterprises Based on Carbon Trading [J]. Logistics Technology, 2014, (5): 372-376. 